\title{
Retrospective Study of Pattern of Fatal Cases of Poisoning in Jodhpur Region
}

\author{
Ashok Danagus ${ }^{*}$, Imran Shaikh², Gyan Prakash Gaur ${ }^{3}$, P.C.Vyas ${ }^{4}$ \\ ${ }^{1 *}$ Assistant Professor, 2 Senior Resident, ${ }^{3}$ Senior Demonstrator, 4 Professor \& H.O.D, \\ Department of Forensic Medicine \& Toxicology, Dr. S.N. Medical College, Jodhpur, Rajasthan, India.
}

\begin{abstract}
Background: Poisoning invariably being medico legal in nature among fatal cases, Post-mortem examination is done to establish the exact cause and manner of death. The aim of this study to know the prevalence of fatal poisoning cases in the study period in Jodhpur region.

Material \& Methods: All Cases of poisoning undergoing medico legal autopsy in the Department of Forensic Medicine Dr. S.N. Medical College and nearby regions and obtaining their chemical analysis from RFSL, Jodhpur, during the study period September 2012 to February 2014. All selected cases were studied for data collection and the proforma was filled for each case.

Results: The maximum numbers of poisoning in the study population are seen in the age group of 31 to 40 years (33\%) followed by age group of 21 to 30 years $(31 \%)$. In the present study, it is observed that the fatal cases of poisoning were seen more amongst the people engaged in Agriculture work (19.00\%) followed by Self Employed (17.00\%), Labourer $(14.00 \%)$, Unemployed (13.00\%), and students, housewives, $(11 \%)$ each. Least were seen among the Professionals (7.00\%).
\end{abstract}

\section{INTRODUCTION}

Poisons have been known from antiquity and were used by ancient tribes and civilization as hunting tools to quicken and ensure death of their prey and enemies. For thousands of years poisons have been used both as a protective tool and a deadly threat around the world. Poisoning has been one of the major causes of unnatural death since the beginning of civilizations. ${ }^{1}$

A poison is a substance which when administered, inhaled, ingested or injected is capable of acting deleteriously on the human body. The word poison has evolved from the Latin word potion meaning "to drink for health" but in due course of time the meaning of the word has changed reversibly to its present form. ${ }^{1}$ In the meantime, new and obscure poisons were beginning to emerge, including many of the legal medical drugs such as fentanyl, insulin, and various muscle relaxants including succinyl choline and pancuronium. New methods of poisoning were introduced, as well as the misuse of common household chemicals such as antifreeze, which was introduced as a murder weapon in 1980's, by Shirley Allen, who used it to kill her husband for insurance money. ${ }^{1}$
Conclusion: In conclusion, everybody first and foremost the physician should be aware of this fact that poisioning are potential public health problems. People making, using, working with poisonous material should be very careful handling with this material.

Key Words: Poisoning, Sucide, Fatal case.

\section{${ }^{*}$ Correspondence to:}

\section{Dr. Ashok Danagus,}

Assistant Professor,

Department of Forensic Medicine \& Toxicology,

Dr. S.N. Medical College, Jodhpur, Rajasthan, India.

Article History:

Received: 18-10-2016, Revised: 02-11-2016, Accepted: 21-11-2016

\begin{tabular}{|l|c|}
\hline \multicolumn{2}{|c|}{ Access this article online } \\
\hline $\begin{array}{l}\text { Website: } \\
\text { www.ijmrp.com }\end{array}$ & Quick Response code \\
\hline DOI: & \\
10.21276/ijmrp.2016.2.6.023 & \\
\hline
\end{tabular}

The incidence of poisoning is increasing day by day because of its low cost, easy availability and insidious nature. Poisoning invariably being medico legal in nature among fatal cases, Postmortem examination is done to establish the exact cause and manner of death. Pattern of poisoning depends upon variety of factors and vary from case to case, region to region, availability and access to poison, popularity, socioeconomic status of individual, knowledge of local population about the poisonous properties of the agent, psychological factors, religious and cultural influences with changes over period of time. ${ }^{2}$

Hence in the present day scenario dealing with poisoning cases involves the knowledge of commonly used poisons, modes of consumption, difficulty in diagnosing, fatal dose, treatment and management modalities.

For which a thorough knowledge in the general pattern of poisoning in a particular region could help in reduction of morbidity and mortality due to poisoning.

So this is a study is taken to analyse the pattern of poisoning and study the common type of poison incidence of poisoning amongst 
the age, sex, socioeconomic distribution and correlate the postmortem findings with the type of poison detected by chemical analysis. ${ }^{2}$ The aim of this study to know the prevalence of fatal poisoning cases in the study period in Jodhpur region.

\section{MATERIAL \& METHODS}

All Cases of poisoning undergoing medico legal autopsy in the Department of Forensic Medicine Dr. S.N. Medical College and nearby regions and obtaining their chemical analysis from RFSL, Jodhpur, during the study period September 2012 to February 2014.

\section{Inclusion criteria}

Cases of alleged history of fatal known poisoning undergoing medico legal autopsy at the place of study during the said study period.

\section{Exclusion criteria \\ Cases where data was incomplete \\ Methods}

All selected cases were studied for data collection and the proforma was filled for each case. Later each case was analysed and compared on various indices and parameters to draw conclusions and observations.

Table 1: Distribution of the study population according to Age.

\begin{tabular}{|c|c|c|c|c|c|c|c|}
\hline S.N. & Age Group & Male & Percent & Female & Percent & Total & Percent \\
\hline 1 & $0-10$ years & 0 & 0.00 & 0 & 0.00 & 0 & 0.00 \\
\hline 2 & $11-20$ years & 5 & 6.09 & 7 & 38.88 & 11 & 12.00 \\
\hline 3 & $21-30$ years & 21 & 25.60 & 10 & 55.55 & 31 & 31.00 \\
\hline 4 & $31-40$ years & 32 & 39.02 & 1 & 5.55 & 33 & 33.00 \\
\hline 5 & $41-50$ years & 18 & 21.95 & 0 & 0.00 & 18 & 18.00 \\
\hline 6 & $51-60$ years & 4 & 4.87 & 0 & 0.00 & 4 & 4.00 \\
\hline 7 & $61-70$ years & 2 & 2.43 & 0 & 0.00 & 2 & 2.00 \\
\hline 8 & $71-80$ years & 0 & 0.00 & 0 & 0.00 & 0 & 0.00 \\
\hline Total & & 82 & 100.0 & 18 & 100.0 & 100 & 100.00 \\
\hline
\end{tabular}

Table 2: Distribution of the study population according to marital status.

\begin{tabular}{lcc}
\hline Marital Status & Number & $(\%)$ \\
\hline Single & 35 & 35.00 \\
Married & 65 & 65.00 \\
Total & 100 & 100.00 \\
\hline
\end{tabular}

Table 3: Distribution of the study population according to Socio-Economic Status.

\begin{tabular}{lcc}
\hline Socio-Economic Status & Number & (\%) \\
\hline SES Class (I) & 4 & 4.00 \\
SES Class (II) & 23 & 23.00 \\
SES Class (III) & 36 & 36.00 \\
SES Class (IV) & 18 & 18.00 \\
SES Class (V) & 19 & 19.00 \\
Total & 100 & $\mathbf{1 0 0 . 0 0}$ \\
\hline
\end{tabular}

Table 4: Distribution of study population according to Occupation.

\begin{tabular}{lcc}
\hline Occupation & Number & $\mathbf{( \% )}$ \\
\hline Agriculture Work & 19 & 19.00 \\
House wife & 11 & 11.00 \\
Professionals & 7 & 7.00 \\
Student & 11 & 11.00 \\
Self Employed & 17 & 17.00 \\
Labourer & 14 & 14.00 \\
Unemployed & 13 & 13.00 \\
Others & 8 & 8.00 \\
TOTAL & 100 & 100.00 \\
\hline
\end{tabular}

\section{RESULTS \& DISCUSSION}

The maximum numbers of poisoning in the study population are seen in the age group of 31 to 40 years (33\%) followed by age group of 21 to 30 years $(31 \%)$. In males, maximum number of poisoning occurred in the age group of 31 to 40 years accounting to $(39.02 \%)$ and age group of 21 to 30 years accounting to $(55.55 \%)$ in females (table 1). Males outnumbered the females in the study population. Similar opinion has been stated by Dalbir Singh $^{3}$, J.Gargi ${ }^{4}$, B.R.Sharma ${ }^{5}$, Murari Atul ${ }^{6}$, S.K. Dhattarwal ${ }^{7}$, Rahul Jain ${ }^{8}$, Manish Nigam ${ }^{9}$ and Sinha US ${ }^{10}$. It is in disagreement with the studies conducted by Taruni $\mathrm{Ng}^{11}$ and Karamjit Singh. ${ }^{12}$

In the present study population, poisoning is seen more among married people (65\%) as compared to unmarried (35\%) (table 2). These findings tallied with the studies conducted by Dalbir Singh ${ }^{3}$, J.Gargi ${ }^{4}$, Karamjit Singh ${ }^{12}$ and S.K.Dhattarwal ${ }^{7}$. These observations were not tallying with the study conducted by B.R.Sharma 5 .

Among the male victims, Married outnumbered the unmarried in both the rural and urban community and even among the female victims, married outnumbered the unmarried in both the rural and urban community.

In case of married males, marital disharmony, family problems, unemployment and financial constraints were the main cause where as in case of married females dowry harassment, dependency on husband, cruelty of in-laws, change of social environment after marriage and family conflicts were the main causes noticed.

In unmarried males' unemployment, frustrations in life, educational problems were the main motive, where as in unmarried females attaining puberty along with physical and metal changes, gender bias, love failures, premenstrual tension were the main reasons. 
According to Prasad's socio-economic status classification- An update for 2014 by Shankar Reddy Dudala, K Ashok Kumar Reddy, G Ravi Prabhu13. It is seen that maximum number of poisoning cases were noticed among SES Class III followed by SES Class II. Least cases were seen among SES Class I (table 3).

In the present study, it is observed that the fatal cases of poisoning were seen more amongst the people engaged in Agriculture work (19.00\%) followed by Self Employed (17.00\%), Labourer (14.00\%), Unemployed (13.00\%),and students, housewives, (11\%) each. Least were seen among the Professionals (7.00\%) (table 4).

As per the present study it is observed that $67 \%$ of the victims died without receiving the treatment, which also included those victims, irrespective of the time of consumption of poison to the period of presenting complaints, causing death of the victim taking only into consideration, this study group of victims didn't receive treatment. Among the treated, $20 \%$ of the victims survived only for $0-12$ hours, $8 \%$ of the victims for $12-24$ hours, $2 \%$ for $1-3$ days \& $2 \%$ for $4-7$ days and the least is one of the victims, who survived for more than 7 days (table 5). The reasons are due to the toxic nature of the poison consumed, individual's response to the poison taken, shortcomings in treatment, and pre-existing diseases among the victims.

Table 5: Distribution of study population according to survival period

\begin{tabular}{lcc}
\hline Survival Period & Number & $\%$ \\
\hline Spot Death / Brought Dead & 67 & 67.00 \\
$\mathbf{0}$ to 12 hrs & 20 & 20.00 \\
12 to 24 hrs & 8 & 8.00 \\
1 to 3 days & 2 & 2.00 \\
4 to 7 days & 2 & 2.00 \\
$>7$ days & 1 & 1.00 \\
TOTAL & 100 & 100 \\
\hline
\end{tabular}

Table 6: Distribution of the study population according to manner of death

\begin{tabular}{lcc}
\hline Manner of Death & Number & $\%$ \\
\hline Suicidal & 53 & 53.00 \\
Alleged Homicide & 9 & 9.00 \\
Accidental & 38 & 38.00 \\
TOTAL & 100 & 100 \\
\hline
\end{tabular}

Table 7: Distribution of the study population according to Type of Poison detected by Chemical Analysis

\begin{tabular}{lcl}
\hline Type of Poison & Number & $\%$ \\
\hline Organophosphorous & 29 & 29.00 \\
Ethyl Alcohol & 26 & 26.00 \\
Ethyl Alcohol+ Organophosphorous & 16 & 16.00 \\
Aluminium Phosphide & 14 & 14.00 \\
Ethyl Alcohol + Opioids & 4 & 4.00 \\
Ethyl Alcohol + Nitrate & 1 & 1.00 \\
Benzodiazepines & 1 & 1.00 \\
Ethyl Alcohol + Aluminium & 5 & 5.00 \\
Phosphide & & \\
Ethyl Alcohol + Carbon Monoxide & 1 & 1.00 \\
Opioids & 1 & 1.00 \\
Carbon Monoxide & 2 & 2.00 \\
\hline
\end{tabular}

In the present study it was observed that, in $53 \%$ of the cases the manner of death were allegedly suicidal, $38 \%$ were accidental and only $9 \%$ were homicidal in nature (table 6 ). In these cases the manner of death was concluded as suicidal, homicidal or accidental based on the history furnished by the police and the relatives of the deceased, suicide note, circumstantial evidence and on the post mortem examination.

The cases detected by chemical analysis $29 \%$ were positive for Organophosphorous, 26\% were positive for Ethyl Alcohol, 16\% were positive for Ethyl Alcohol+ Organophosphorous, 14\% were positive for Aluminium Phosphide, 4\% were positive for Ethyl Alcohol + Opioids, $1 \%$ were positive for Ethyl Alcohol + Nitrate, $1 \%$ were positive for Benzodiazepines, $5 \%$ were positive for Ethyl Alcohol + Aluminium Phosphide, 1\% were positive for Ethyl Alcohol + Carbon Monoxide, $1 \%$ were positive for Opioids \& 2\% were positive for Carbon Monoxide (table 7).

Alcohol was used as a additive component with consumption of Organophosphorous, Aluminium Phosphide, Nitrate, and Opioids in 26 cases. The analytical methods employed at Regional Forensic Science Laboratory, Jodhpur for the detection of various poisons were colour test and Thin Layer Chromatography. Colour test and volumetric methods responded for the presence of Alcohol and the highest percentage of alcohol detected is 144.43 $\mathrm{mg} / 100 \mathrm{ml}$ of blood and the least percentage of alcohol is 31.83 $\mathrm{mg} / 100 \mathrm{ml}$ of blood. The reason for more number of victims to choose organophosphorus were due to low cost, easy availability of highly toxic pesticide, agriculture based economics and to the fact that poisoning by agro-chemical is practically inevitable because modern farming is unthinkable without the use of these and especially for a developing country like ours.

\section{CONCLUSION}

In conclusion, everybody first and foremost the physician should be aware of this fact that poisoning are potential public health problems. People making, using, working with poisonous material should be very careful handling with this material. It should bear in mind that poisonous has medical as well as legal aspect. Public education campaigns especially about pesticide poisoning should be conducted and the target population should be identified and reached in this campaigns.

\section{REFERENCES}

1. Sibia RS, Kumar S A, Bhullar DS, Pillai GS, Sharma H, Sandhu SS. Poisoning trends at a tertiary hospital: A retrospective analysis. J Punjab Acad Forensic Med Toxicol 2014; 14:19-21.

2. Krishan Vij, Text Book Of Forensic Medicine And Toxicology. 2nd Edition, B.I. Churchill Livingstone, New Delhi; 2002:760-968.

3. Dalbir Singh, Seema J, Tyagi I. Changing Trends in Acute Poisoning in Chandigarh Zone. The American Journal of Forensic Medicine and Pathology,1999;20(2);203-210.

4. Gargi J, Hakumat Rai, Ashok Chanana, Gurmanjit Rai, Bagga I.J.S. Current Trends Of Poisoning- A Hospital Profile. Journal Of Punjab Forensic Medicine And Toxicology, 2003; 3:41-45.

5. Sharma B.R, Dasari Harish, Vivek Sharma, Krishan Vij. The Epidemiology Of Poisoning: An Indian View Point. Journal Of Forensic Medicine and Toxicology, 2002; 19(2): 5-11.

6. Murari Atul, Sharma G.K A Comparative Study of Poisoning Cases Autopsied in LHMC, New Delhi and JIPMER, Pondicherry. Journal of Forensic Medicine and Toxicology, 2002; 19 (1): 18-20. 
7. Dhattarwal S.K, Harnam Singh. Profile of Deaths Due To Poisoning In Rohtak, Haryana. Journal of Forensic Medicine and Toxicology, 2001; 18 (2) 28-29.

8. Rahul Jain, Sharikanth Asawa, Shishir Ruia. Status of Poisoning In A Hospital Of Maharashtra. Journal of Forensic Medicine and Toxicology, 2001; 18 (1): 12-16.

9. Manish Nigam, Ashok Kumar Jain, Dubey B.P, Sharma V.K. Trends Of Organophosphorus Poisoning In Bhopal Region An Autopsy Based Study. Journal of Indian Forensic Medicine, 2004; $26(2): 62-65$.

10. Sinha US, Kapoor AK, Agnihotri, Srivastava PC. A Profile of Poisoning cases Admitted In SRN Hospital, Allahabad With Special Reference To Aluminium Phosphide Poisoning, Journal of Forensic Medicine and Toxicology,1999;16 (1):40-42.

11. Taruni Ng, Bijoy Th, Momonchand A. A Profile of Poisoning cases admitted In RIMS Hospital, Imphal. Journal of Forensic Medicine and Toxicology, 2001; 18(1): 31-33.

12. Karamjit Singh, Oberoi S.S, Bhullar D.S. Poisoning Trends In The Malwa Region Of Punjab. Journal Of Punjab Forensic Medicine and Toxicology, 2003; 3:26-29.
13. Shankar Reddy Dudala, K Ashok Kumar Reddy, G Ravi Prabhu, Prasad's socio-economic status classification- An update for 2014.

\section{Source of Support: Nil.}

Conflict of Interest: None Declared.

Copyright: (c) the author(s) and publisher. IJMRP is an official publication of Ibn Sina Academy of Medieval Medicine \& Sciences, registered in 2001 under Indian Trusts Act, 1882.

This is an open access article distributed under the terms of the Creative Commons Attribution Non-commercial License, which permits unrestricted non-commercial use, distribution, and reproduction in any medium, provided the original work is properly cited.

Cite this article as: Ashok Danagus, Imran Shaikh, Gyan Prakash Gaur, P.C.Vyas. Retrospective Study of Pattern of Fatal Cases of Poisoning in Jodhpur Region. Int J Med Res Prof. 2016; 2(6):117-20. DOI:10.21276/ijmrp.2016.2.6.023 